\title{
Surgical management of eumycetoma: experience from Gezira Mycetoma Center, Sudan
}

\author{
Mohamed D. A. Gismalla 1* (D), Gamal M. A. Ahmed ', Mogahid M. MohamedAli ${ }^{1}$, Sami M. Taha', \\ Thouria A. Mohamed ${ }^{2}$, Ahmed E. Ahmed ${ }^{2}$ and Lamia S. Hamed ${ }^{2}$
}

\begin{abstract}
Background: In this study, we share our experience of different operative techniques undertaken on 584 eumycetoma patients in the Gezira Mycetoma Center.

Methods: This is a retrospective, descriptive, hospital-based study, conducted to review the surgical treatment of eumycetoma patients. We included all patients diagnosed with eumycetoma who underwent a surgical operation in the center during January 2013-December 2016.

Results: A total number of 1654 patients were seen during the study period, and their records were revised, while 584 (35.3\%) of them underwent an operation and included in the study. There was a male predominance 446 (76.4\%). Surgical excision of mycetoma was the commonest operation performed among 513 (87.8\%) patients in comparison with amputation 71 (12.2\%). Below-knee amputation and toe amputation are the commonest types of amputation in $36(6.1 \%)$ and $14(2.3 \%)$ patients, respectively. Clinical features determining the type of operation performed included the size of the lesion, whether or not a bone was involved, and the feasibility of primary closure. A wide surgical excision (WSE) is performed mainly when the bone is not involved and when moderate or primary closure is possible or reconstruction is feasible. Amputations will typically follow identifying bone involvement, secondary infection, and an already disabled patient.

Conclusion: The commonest procedure in our series was WSE and primary skin closure undertaken when the lesion was small $(<5 \mathrm{~cm})$; there was no bone involvement, and the skin closure was achievable. Larger lesions $(>10 \mathrm{~cm})$ without bone involvement were treated with excision and flap/graft. Bone involvement and large primary lesions were more likely to be managed by amputation. Recurrent and relapse of mycetoma were observed in patients with bone involvements or presented with recurrent mycetoma for the second time.
\end{abstract}

Keywords: Amputations, Eumycetoma, Mycetoma, Sudan, Surgical excision, Surgery

\section{Background}

Recently, mycetoma was recognized by the World Health Organization as a neglected tropical disease. It is defined as a chronic skin and subcutaneous swelling caused either by eumycetoma or actinomycetoma [1]. It has a worldwide distribution but is endemic in tropical and subtropical countries across the "mycetoma belt." This runs from India to Yemen and goes through Sudan,

\footnotetext{
* Correspondence: mohadaff22@gmail.com

1 Department of surgery, Faculty of Surgery, Gezira University, Wad Medani, Gezira, Sudan

Full list of author information is available at the end of the article
}

Senegal, and onto South America and Mexico [2]. In Sudan, mycetoma is common in Gadarif, Kassala, Sinnar, Gezira, Khartoum, Kordofan, and Darfur states. Gezira state was recognized as having one of the highest incidences of mycetoma. Fahal et al. conducted a review of their experience from the Mycetoma Research Center from 1991 to 2014. They reported that of the 2476 patients attending the center, $792(31.9 \%)$ were from Gezira state [3].

Management of mycetoma is determined mainly by the causative organism infections. Actinomycetoma responds well to medical treatments like Septrin and 
vancomycin. Surgery has a limited role and is mainly used for unresponsive cases or combined with medical treatments [4]. In contrast, eumycetoma has a poor response to medical therapy (anti-fungal such as azoles). Recently, itraconazole has been used in doses of 100$200 \mathrm{mg}$ per day for 6-12 months with/or without combination with surgical management [5]. In the absence of effective medical treatment for eumycetoma, surgical approaches are all that is available. The commonest surgical option is wide surgical excision which is recommended for small well-circumscribed lesions $(\geq 5 \mathrm{~cm})$ [6]. The other options are wide surgical excision plus flap can be done for big lesions when primary closure is not applicable and amputation can be done for toes, fingers, or big complicated limbs (hand or foot) [7].

Classification of the causative organism is undertaken by microscopic examination of the grains or using fine-needle aspirations cytology. This will show the non-caseating granulomatous inflammatory feature [8]. Once eumycetoma is established as the cause, the second most important step is to determine the local extension of the disease and evaluation of bone status by using radiological techniques [9]. In spite of bridging the gap of knowledge by mycetoma group, still the management's outcome is not promising; there is a lack of detailed indications, types, and surgical techniques toward mycetoma [10]. The treatment depends mainly on physician preference and experience. These raise the need for global or regional guidelines.

Gezira Mycetoma Center was established in 2012 after Memorandum Corporation between Blue Nile National Institute for Communicable Disease, Gezira University, and Gezira State Ministry of Health, Sudan Federal Ministry of Health, Sudan Ministry of Social Welfare and Health Insurance Corporation [11]. It covers the Gezira state and other nearby states. A total number of $60-80$ patients are seen per month in the referred clinic with 20 to 30 operations undertaken each week. In this study, we share our experience of the different operative techniques used to treat our eumycetoma patients, looking at the factors that determine the choice of operation, at Gezira Mycetoma Center.

\section{Methods}

\section{Study design}

This is a retrospective, descriptive, hospital-based study, conducted during January 2013-December 2016 to review the surgical treatment of eumycetoma patients. All patients' records were reviewed during the study period.

\section{Inclusion criteria}

We included all patients who are diagnosed with eumycetoma (fungal) and underwent surgical treatment in the center during the study period.

\section{Exclusion criteria}

Any patient operated in other hospitals, has unresectable eumycetoma lesions, or has actinomycetoma was excluded.

\section{Diagnostic evaluation}

Clinical assessment is undertaken for all patients presenting to the center. These evaluations determine the history of the lesion, duration, presence, and color of the grain as well as a local and regional examination of the limp or mass. Then, imaging radiological study is performed to patients to evaluate the bone status and soft tissue swelling.

Diagnosis of eumycetoma or actinomycetoma includes fine-needle aspiration cytology and histological diagnosis and clinical evaluation (discharging grain or sinuses). A histological examination can be done by using hematoxylin and eosin (H\&E) stain which shows the non-caseating granulomatous necrosis. If the result is not conclusive, other stains can be used like periodic acid-Schiff and methylamine silver stains. The final result in our clinical work cannot define the subspecies for each group.

\section{Operative techniques}

Preoperative clinical evaluation, routine urine samples, blood test, and X-rays were performed according to each patient's condition. The choice of anesthesia was typically spinal or general anesthesia according to the lesion site or age of the patients. For the upper or lower limb lesion, tourniquet had been used almost all the time

Table 1 Characteristics of patients in the study $(N=584)$

\begin{tabular}{llll}
\hline Variables & & Frequency & Percent \\
\hline Age distribution & $<10$ & 29 & 4.9 \\
& $10-19$ & 63 & 10.7 \\
& $20-40$ & 279 & 47.7 \\
Sex & $>40$ & 213 & 36.7 \\
Residence state & Male & 446 & 76.4 \\
& Female & 138 & 23.6 \\
& Gezira State & 472 & 80.8 \\
& Sinnar State & 42 & 7.2 \\
& Gadarif State & 24 & 4.2 \\
& Kassala State & 15 & 2.5 \\
& Others & 31 & 5.3 \\
Occupation & Farmer & 214 & 36.7 \\
& Animal breeder & 84 & 14.4 \\
& Housewife & 103 & 17.7 \\
Recurrent mycetoma & Student & 182 & 31.2 \\
& Yes & 94 & 16.1 \\
& No & 490 & 83.9 \\
\hline
\end{tabular}


Table 2 Factors associated with types of surgical operation $(N=584)$

\begin{tabular}{|c|c|c|c|c|c|c|}
\hline & & Total & Wide surgical excision & WSE graft or flap & Amputation & $p$ value \\
\hline \multirow[t]{3}{*}{ Size } & Small, $5 \mathrm{~cm}$ & 491 & 472 & 0 & 19 & $<0.01$ \\
\hline & Moderate, $5-10 \mathrm{~cm}$ & 35 & 7 & 21 & 7 & \\
\hline & Big, more than $10 \mathrm{~cm}$ & 35 & 2 & 11 & 45 & \\
\hline \multirow[t]{2}{*}{ X-ray } & Bone involve & 101 & 0 & 30 & 71 & $<0.01$ \\
\hline & Bone not involve & 483 & 481 & 2 & 0 & \\
\hline \multirow[t]{2}{*}{ Sinus } & Yes & 461 & 358 & 32 & 71 & $<0.01$ \\
\hline & No & 123 & 123 & 0 & 0 & \\
\hline Total & & 584 & 481 & 32 & 71 & \\
\hline
\end{tabular}

while in cases of a trunk mycetoma, diathermy has been used. Careful surgical dissection was performed to excise the lesion completely, followed by washing and irrigation of surgical site with normal saline and iodine solution. Amputation of the toes, fingers, forearm, or leg was taken only after counseling and discussion with the patient.

The hospital stay was $2-3$ days. Outpatient reviews were at 2 weeks, 1 month, and 3 months till 6 months, 12 months, and 18 months. Wound healing, deformity, and recurrence were checked during these periods. Itraconazole tablets $200-400 \mathrm{mg}$ (anti-fungal agents) were given routinely perioperatively according to Suleiman et al.'s guideline (Mycetoma Research Center, Khartoum) [6]. For small-sized mycetoma $\leq 5 \mathrm{~cm}$, we give itraconazole tablets only postoperatively for 3 months while for moderateand big-sized lesion $\geq 5 \mathrm{~cm}$, patient receives the treatments for 6 months before and after the operation.

\section{Data collection and analysis}

Flowchart sheets were used to collect the data. Age, sex, residence, and occupation were checked. Information regarding the presence of sinus (grains), recurrence mycetoma, and X-ray evaluations was determined. Types of operation done and factors to select each operation were determined.

\section{Results}

Patients' characteristics were shown in Table 1. A total number of patients who were included in this study were

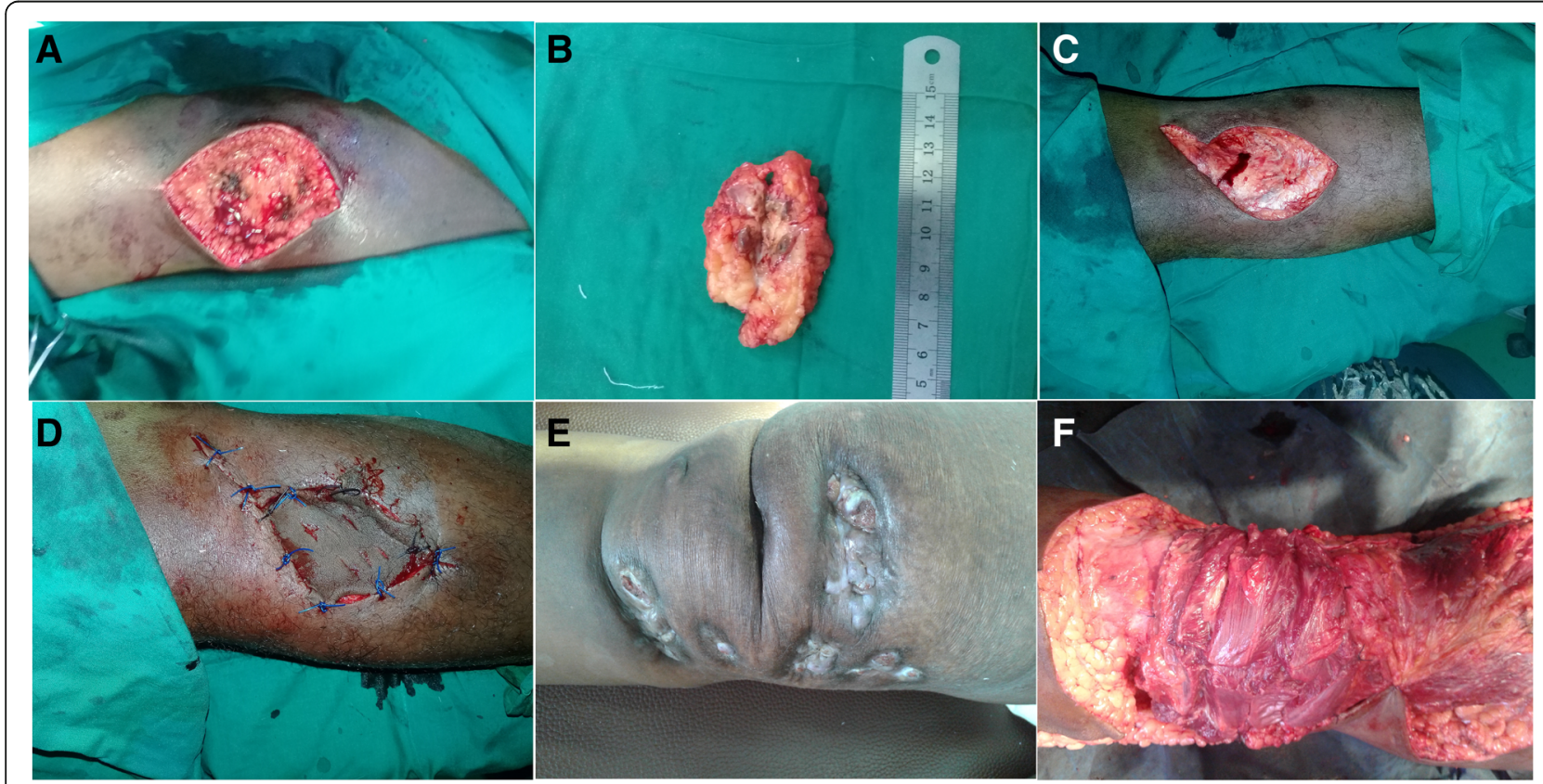

Fig. 1 Wide surgical excision (WSE) and primary closure, skin graft, or flap. a WSE with a margin of mycetoma lesion. b The excised same lesion which measures about $6 \mathrm{~cm}$. c, d WSE with margin defect closed with skin graft. e Recurrent knee mycetoma. $\mathbf{f}$ Reconstruction after excision with gastrocnemius flap 


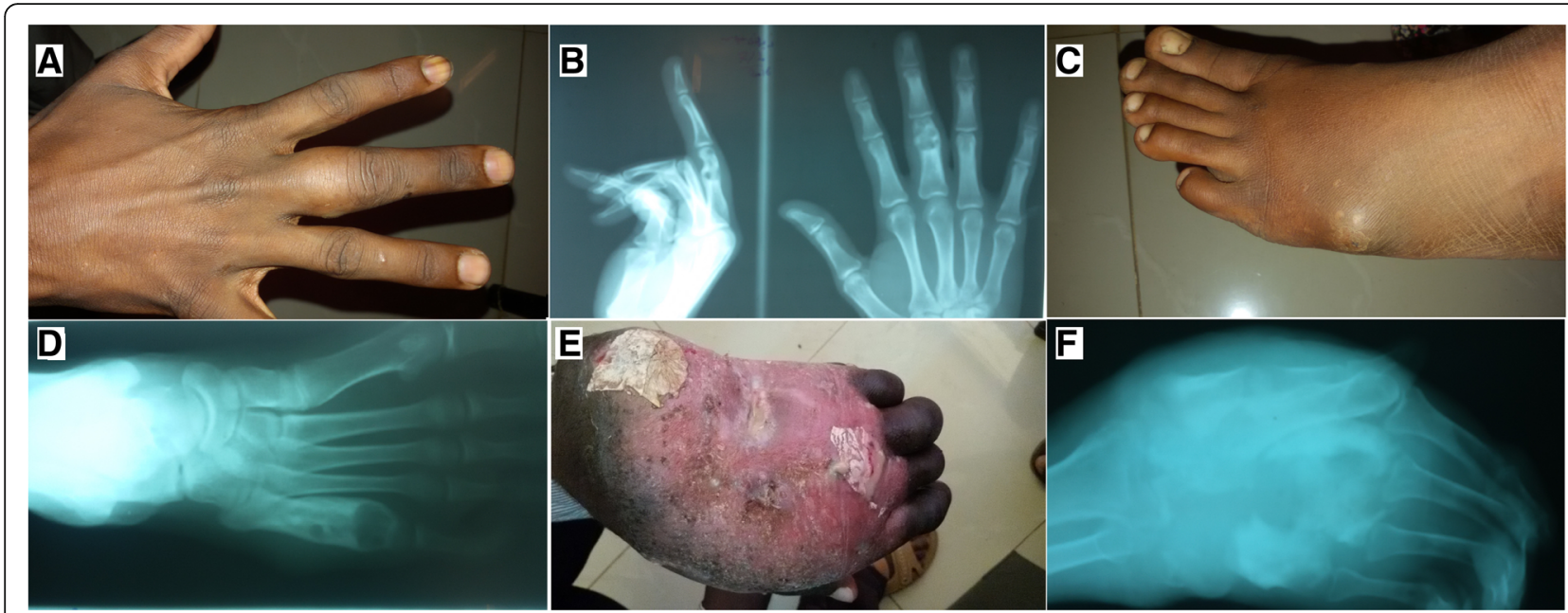

Fig. 2 Pre-amputation images of the finger, toe, and hand with X-ray showing mycetoma. a Right middle finger eumycetoma (proximal phalanx). b PA and lateral X-ray view of the same patients showing cavity and evidence of mycetoma (this patient treated by finger Ray's amputation). c Left toe mycetoma with sinus cavity. $\mathbf{d}$ X-ray was showing cavity and mycetoma (this patient treated by toe Ray's amputation). e Hand showing mycetoma deformity, discoloration, and loss of function. $\mathbf{f}$ X-ray of the same patient was showing a deformity, cavitation, and mycetoma (this patient treated by below-elbow amputation)

584. The median range of follow-up was 18 months (range between 12 and 24 months). The total number of patients who are less than 20 years of age is $92(14.6 \%)$. The male patients are predominant with $446(76.4 \%)$. Most of the patients in this study reside in Gezira state (472 (80.8\%)). Farmers (214 (36.7\%)) and (182 (31.2\%)) students were the commonest jobs among patients in the study. Patients who had recurrent mycetoma and recruited in this study are $94(16.1 \%)$. Discharging grains and sinus were found in 461 patients $(78.9 \%)$. Radiological evaluations revealed that bone was not involved in 483 (82.7\%) patients.

Surgical excision of mycetoma was the commonest operation done in the center among 513 (87.8\%) patients in comparison with amputation which performed between $71(12.2 \%)$ patients (Table 2). Wide surgical excision and primary closure was the commonest surgical operation, and it was done in 480 (82.4\%) patients. Below-knee amputation and toe amputation are the commonest types of amputation in $36(6.2 \%)$ and 14 (2.4\%) patients, respectively.
There were several factors which are believed to determine the type of surgical operation in our series. Wide surgical excision and primary closure depended on the size of the lesion, bone not involved, and feasibility of primary closure (Fig. 1; Table 2). Wide surgical excision (WSE) plus skin graft or flap (Fig. 1) depends on bone involvements, moderate or big size, and feasibility of reconstruction. Factors which determine the selection of amputation are bone involvement, secondary infection, disability of patients, and patients request options (Fig. 2; Table 3).

There is a significant statistical relation between the size of the tumor and bone involvements and selection of patients. After an average period of follow-up (18 months), the recurrence rate among those patients is $32(5.5 \%)$. There is a significant relation between recurrent mycetoma in our patients in this study and bony involvement, recurrence mycetoma, types of operation, and size of the lesion shown in Table 4.

Table 3 Factors associated with types of amputations $(N=71)$

\begin{tabular}{llllllll}
\hline & & Total & BKA & AKA & Elbow amputation & Syme's amputation & Ray's amputation \\
\hline Secondary infection & Yes & 25 & 13 & 3 & 3 & 5 & 1 \\
& No & 46 & 23 & 1 & 0 & 4 & 15 \\
Cannot walk (disability) & Yes & 52 & 36 & 4 & 3 & 9 & 0 \\
& No & 19 & 0 & 0 & 0 & 0 & 19 \\
Patient request & Yes & 19 & 0 & 0 & 0 & 0 & 19 \\
& No & 52 & 36 & 4 & 3 & 9 & 0 \\
\hline
\end{tabular}


Table 4 Factors associated with recurrent mycetoma $(N=584)$

\begin{tabular}{|c|c|c|c|c|c|}
\hline & \multirow[t]{2}{*}{ Variables } & \multicolumn{2}{|c|}{ Recurrence after surgery } & \multirow[t]{2}{*}{ Total } & \multirow[t]{2}{*}{$p$ value } \\
\hline & & Yes & No & & \\
\hline \multirow[t]{2}{*}{ Bone involvements } & Yes & 12 & 89 & 101 & \multirow[t]{2}{*}{$<0.01$} \\
\hline & No & 20 & 463 & 483 & \\
\hline \multirow[t]{2}{*}{ First recurrence mycetoma ${ }^{a}$} & Yes & 16 & 78 & 94 & \multirow[t]{2}{*}{$<0.01$} \\
\hline & No & 16 & 474 & 490 & \\
\hline \multirow[t]{3}{*}{ Operation } & Wide surgical excision & 18 & 463 & 481 & \multirow[t]{3}{*}{$<0.01$} \\
\hline & WSE graft or flap & 8 & 24 & 32 & \\
\hline & Amputation & 6 & 65 & 71 & \\
\hline \multirow[t]{3}{*}{ Size } & Small, $5 \mathrm{~cm}$ & 17 & 474 & 491 & \multirow[t]{3}{*}{$<0.01$} \\
\hline & Moderate, 5-10 cm & 7 & 28 & 35 & \\
\hline & Big, more than $10 \mathrm{~cm}$ & 8 & 50 & 58 & \\
\hline
\end{tabular}

${ }^{\mathrm{a}}$ Patient presented to the center with already recurrent mycetoma

\section{Discussion}

Most of the patients in this study underwent wide surgical excision and primary closure. Surgical excision is the treatment of choice for treating eumycetoma if it is achievable. The characters these patients most likely to do well here are those with small lesions and without bone involvements [12]. Surgical excision needs a careful surgical dissection in a bloodless field and an experienced hand to reduce the recurrence [6]. Surgical excision and reconstruction by flap and/or graft can be done for moderate or large lesions when bone is not involved and the primary closure is not feasible [7].

Eumycetoma is a disfiguring and disabling disease. It is the third leading cause of amputation in Sudan after diabetic-related problems (infection and vascular) and trauma [13]. Although amputation is avoided as much as possible in Sudan, it is indicated among mycetoma patients in about $25-50 \%$ of cases. The published rate of amputations for mycetoma worldwide ranges from 25 to $50 \%[13,14]$. In this study, the commonest amputations are below-knee and toe amputations. Limb amputation is performed for huge eumycetoma $(\geq 10 \mathrm{~cm})$, with a secondary bacterial infection, to save patient life [14]. In our series, amputation of toes and fingers were undertaken to achieve cure, when bone was involved and WSE not possible. Limb amputation was done for disfiguring lesions, secondary infection, and patients already unable to walk.

Bone status should be determined in any mycetoma patients especially eumycetoma. The radiological study is cheap, available, and easy to interpret. In Sudan, Fahal et al. [15] reported bone involvement among 73\% of mycetoma patients; the radiological abnormality varies from soft tissue mass and bone destruction to periosteal reactions. Any patient without bone involvements has a better chance to be cured. In this study, we depended mainly on radiological (X-ray) evaluation of bone. Then, patients are categorized into two main groups (bone involvements or not involved). According to the bone status, we can judge the types of operation that can be offered to the patient. If a bone is not involved wide surgical excision can be chosen or amputations for bone involvements.

In this study, the commonest operation for eumycetoma is wide surgical excision and primary skin closure. This operation was selected due to the small-sized lesion (less than $5 \mathrm{~cm}$ ), no bone involvements, and the skin can be closed easily. Any big-sized lesion without bone involvements can be treated with excision and flap/graft. Bone involvements with massive mycetoma are predicting factors for amputation.

\section{Conclusion}

This study highlights the factors which determine surgical management choices for eumycetoma in Sudan. Which operation is chosen mainly depends on the size of the lesion and bone involvements. Amputations were performed among patients with huge lesions, disabled, and requested amputation for cure. One of the limitations of this study is that we did not analyze the other factors which can affect the outcome like time of presentation, preoperative medication, and subspecies of mycetoma.

Abbreviations

WSE: Wide surgical excision

\section{Acknowledgements}

The authors would like to thank the patients' record team and all Gezira Mycetoma Staff. Additionally we thanks Mr. Mohamed A Salih for grammar reviewing.

\section{Funding}

This study received no specific grant from any funding agency in the public, commercial or not-for-profit sectors.

\section{Availability of data and materials}

The dataset and materials of the current study are available through the corresponding author on reasonable request. 


\section{Authors' contributions}

MDAG conceived the idea and designed the study. TAM, AEA, and LSH did the data collection and analysis. MDAG, GMAA, MMMA, and SMT wrote the manuscript and made final approval. All authors read and approved the final manuscript.

\section{Ethics approval and consent to participate}

Ethical approval was obtained from Gezira Mycetoma Centre. Consent was obtained from all patients including using photos for medical and research purposes.

\section{Consent for publication}

The consent for publication was obtained from each study participants during data collection.

\section{Competing interests}

The authors declare that they have no competing interests.

\section{Publisher's Note}

Springer Nature remains neutral with regard to jurisdictional claims in published maps and institutional affiliations.

\section{Author details}

'Department of surgery, Faculty of Surgery, Gezira University, Wad Medani, Gezira, Sudan. ${ }^{2}$ Gezira Mycetoma Center, Ministry of Health, Wad Medani, Gezira, Sudan.

Received: 12 October 2018 Accepted: 18 December 2018

Published online: 14 January 2019

\section{References}

1. Zijlstra EE, Van De Sande WW, Fahal AH. Mycetoma: a long journey from neglect. PLoS Negl Trop Dis. 2016;10(1):e0004244. https://doi.org/10.1371/ journal.pntd.0004244.

2. Fahal AH, Sabaa AA. Mycetoma in children in Sudan. Trans Royal Soc Trop Med Hyg. 2010;104(2):117-21.

3. Fahal A, Mahgoub ES, Hassan AME, Abdel-Rahman ME. Mycetoma in the Sudan: an update from the Mycetoma research Centre, University of Khartoum. Sudan PLoS Negl Trop Dis. 2015;9(3):e0003679. https://doi.org/10. 1371/journal.pntd.

4. Welsh O, Al-Abdely HM, Salinas-Carmona MC, Fahal AH. Mycetoma medical therapy. PLoS Negl Trop Dis. 2014;8(10):e3218. https://doi.org/10.1371/ journal.pntd.0003218.

5. Fahal AH, Rahman IA, El-Hassan AM, Rahman MA, Zijlstra EE. The safety and efficacy of itraconazole for the treatment of patients with eumycetoma due to Madurella mycetomatis. Trans Royal Soc Trop Med Hyg. 2011;105(3):127-32.

6. Suleiman $\mathrm{SH}$, Wadaella ES, Fahal AH. The surgical treatment of mycetoma. PLoS Negl Trop Dis. 2016;23:10

7. Gismalla MD, Abdulla GM, Ali MM, Mohamed SM. Wide surgical excision and reconstruction of eumycetoma in Gezira Mycetoma Centre. Global J Med Res. 2017;16:15-7.

8. Nenoff $P$, van de Sande WW, Fahal AH, Reinel D, Schöfer H. Eumycetoma and actinomycetoma — an update on causative agents, epidemiology, pathogenesis, diagnostics and therapy. J Eur Acad Dermatol Venereol 2015; 29:1873-1883, DOl: https://doi.org/10.1111/jdv.13008.

9. van de Sande WW, Fahal AH, Goodfellow M, Welsh O, Zijlstra EE. Merits and pitfalls of currently used diagnostic tools in mycetoma. PLoS Negl Trop Dis. 2014;8:2918.

10. van de Sande W, Fahal A, Ahmed SA, Serrano JA, Bonifaz A, Zijlstra E, Eumycetoma Working Group. Closing the mycetoma knowledge gap. Med Mycol. 2018;56(suppl_1):153-64.

11. University of Gezira, Blue Nile Institute for Communicable Disease, Gezira Mycetoma Center [Internet]. Bnnicd.uofg.edu.sd. 2018 [cited 12 Dec 2018]. Available from: http://bnnicd.uofg.edu.sd/EN/Department.aspx?dep=7

12. El-Sobky TA, Haleem JF, Samir S. Eumycetoma osteomyelitis of the calcaneus in a child: a radiologic-pathologic correlation following total calcanectomy. Case Rep Pathol. 2015;2015:129020.

13. Shaheen S. Patients with lower limb amputations for mycetoma in the National Center for Prosthetics and Orthotics in the Sudan. Khartoum Med J. 2008;1:27-9.
14. Fahal $\mathrm{AH}$, Shaheen $\mathrm{S}$, Jones $\mathrm{DH}$. The orthopaedic aspects of mycetoma. Bone Joint J. 2014:96(3):420-5.

15. Fahal A, Mahgoub ES, Hassan AM, Abdel-Rahman ME. Mycetoma in the Sudan: an update from the Mycetoma Research Centre, University of Khartoum, Sudan. PLoS Negl Trop Dis. 2015;9(3):e0003679. https://doi.org/ 10.1371/journal.pntd.0003679.
Ready to submit your research? Choose BMC and benefit from:

- fast, convenient online submission

- thorough peer review by experienced researchers in your field

- rapid publication on acceptance

- support for research data, including large and complex data types

- gold Open Access which fosters wider collaboration and increased citations

- maximum visibility for your research: over $100 \mathrm{M}$ website views per year

At BMC, research is always in progress.

Learn more biomedcentral.com/submissions 